University of Warwick institutional repository: http://go.warwick.ac.uk/wrap This paper is made available online in accordance with publisher policies. Please scroll down to view the document itself. Please refer to the repository record for this item and our policy information available from the repository home page for further information.

To see the final version of this paper please visit the publisher's website. access to the published version may require a subscription.

Author(s): Dieter Wolke, Sarah Woods, and Muthanna Samara Article Title: Who Escapes or Remains a Victim of Bullying in Primary School?

Year of publication: 2008

Link to published version:

Publisher statement: None 


\section{Who Escapes or Remains a Victim of Bullying in Primary School?}

Dieter Wolke $^{1,3}$, Sarah Woods $^{2}$, and Muthanna Samara ${ }^{1}$

British Journal of Developmental Psychology, in press

${ }^{1}$ University of Warwick, Department of Psychology ${ }^{2}$ University of Hertfordshire, School of Psychology ${ }^{3}$ University of Warwick, Health Science Research Institute, Warwick Medical School

Word count (exc. figures/tables): 6,219 (without references and tables)

${ }^{*}$ Requests for reprints should be addressed to Professor Dieter Wolke, University of Warwick, Department of Psychology and Health Sciences Research Institute, Warwick Medical School, Coventry, CV4 7AL, United Kingdom (e-mail: D. Wolke@warwick.ac.uk).

Acknowledgements: The study was partly supported by a project grant from the Economic and Social Science Research Council (ESRC) (award No.: R000222563).

We would like to thank our co-workers and interviewers who contributed to the study:

Katherine Stanford, Anna Marsden and Linda Bloomfield. We are indebted to the head teachers, teachers and the children who made this study possible. 


\title{
Who Escapes or Remains a Victim of Bullying in Primary School?
}

\author{
Abstract \\ The stability of both direct and relational victimisation and factors that contribute to \\ remaining, escaping or becoming a victim of bullying were investigated. 663 children \\ at baseline aged 6-9 (years 2-4) were interviewed about their bullying experiences and \\ parents completed a behaviour and health measure. Children's perception of the \\ degree of social hierarchical structuring and social prominence in their class was \\ determined by peer nominations. 432 children participated in the follow-up either 2 or \\ 4 years after baseline aged 10-11 (year 6) and completed a bullying questionnaire. \\ Relational victims and children from classes with a high hierarchical structure were \\ more likely to have dropped out of the study compared to neutral children, and \\ children from classes with a low hierarchical structure. Relative risk analyses \\ indicated a two-fold increased risk of remaining a direct victim at follow-up, \\ compared to a child not involved at baseline becoming a victim over the follow-up \\ period. In contrast, relational victimisation increased but was not found to be stable. \\ Logistic regression analyses revealed that being a girl, and receiving few positive peer \\ nominations predicted remaining a direct victim. Becoming a relational victim at \\ follow-up was predicted by a strong class hierarchy. The implications for future study \\ of early recognition of likely long term victims and early preventative bullying \\ initiatives are discussed.
}




\section{Introduction}

Bullying victimisation refers to a student being exposed to negative actions on the part of one or more other students with the intention to hurt. Bullying must be a repeated action and occur regularly over time (Olweus, 1999) and it usually involves an imbalance in power, either real or perceived (Craig, 1998; Whitney \& Smith, 1993). Victimisation can be physical, including acts such as being hit or beaten and physical or verbal threats, often referred to as direct victimisation, or relational defined as the purposeful damage and manipulation of peer relationships leading to social exclusion by spreading malicious gossip or withdrawal of friendships (Crick \& Grotpeter, 1995; Wolke, Woods, Bloomfield, \& Karstadt, 2000).

Recently, studies have begun to address the issue of stability of bullying victimisation, and the risk factors associated with becoming involved in, remaining involved in, or escaping victimisation (Cote, Vaillancourt, Barker, Nagin, \& Tremblay, 2007; Crick, Ostrov, \& Werner, 2006; Pellegrini \& Long, 2002). There is general agreement that the prevalence of victims decreases but the stability of victimisation increases in the adolescent years (Coyne, Archer, \& Eslea, 2004; Olweus, 1978; Perry, Kusel, \& Perry, 1988). Continued victimisation among adolescent samples have typically found that these individuals tend to have few friends, high absenteeism from school, and significant behaviour problems (e.g. Smith, Talamelli, Cowie, Naylor, \& Chauhan, 2004). In contrast, there are mixed findings regarding stability, in particular, of the victim role during primary school years. Some have reported that bullying among primary school children is a moderately stable behaviour over a school year and transition to the next school year (Boulton \& Smith, 1994; Boulton \& Underwood, 1992). Others have found low 
stability of victimisation during primary school years using various methodologies. For example, Kochenderfer-Ladd and Waldrop (2001) found that from kindergarten to third grade, only $4 \%$ occupied the victim role at all four time points of measurement using self-reports. Similarly, Schäfer and Albrecht (2004) who used a pictorial self-report found low stability over a period of a month. A lack of stability has also been found using peer reports of victim roles (Monks, Smith, \& Swettenham, 2003). A further key issue is that the majority of studies to date have solely focused on direct victimisation, and have not explored the stability of relational victimisation among young children.

Two proposals have been put forward to explain why a significant number of children are chronically victimised and others move in and out of different roles. Firstly, theories related to variations in peer structure and dominance hierarchies may account for differences in the stability of victimisation roles (Pellegrini \& Long, 2002). Schäfer, Korn, Brodbeck, Wolke and Schulz (2005) suggested that the clearer the hierarchical dominance structure has been formed in social interactions and social cognitions, the less likely it is to escape from the victim role in the class. The victims' escape is hampered by their weaker role in a strong social ranking hierarchy. They proposed that peer hierarchies, as a group level construct can be measured by the children's shared perceptions of the degree of social structuring in their class. This can be indexed by differential social prominence within the class, and represented on the class level by determining the within class variance of social impact scores (Coie, Dodge, \& Coppotelli, 1982). The larger the variance the stronger the established peer hierarchies within a class. Schäfer et al. (2005) found that victims in primary school classes with a more pronounced hierarchical structure proved more stable in their 
victim role from primary to secondary school, compared to those from classes with lower social hierarchies. Thus, the social context appears to be an important influence already in primary school for continued victimisation status.

Secondly, individual child characteristics in addition, or in interaction with social factors may account for children remaining or escaping the victim role. These include the development of proactive and adaptive coping strategies that enable children to cope more successfully with victimisation attempts. Those who continue to be victimised are likely to have less effective coping skills (Smith, Shu, \& Madsen, 2001). Coping behaviour can draw on both internal resources (self-esteem, physical and emotional health, intelligence, personality) and external resources (social support, changes in the environment) (Maes, Leventhal, \& de Ridder, 1996). There is considerable evidence that victims lack the necessary internal resources that allow them to deal with bullying incidents effectively, or to rally the social support and make friendships to fend off bullies (Boulton \& Smith, 1994; Olweus, 1993; Schuster, 1996). Hodges, Malone, and Perry (1997) have argued that there are three prominent external resources in relation to social network factors that contribute to prolonged victimisation: 1) few friends, 2) quality of friends (such as their peer status), and 3) general standing in the peer group (specifically extent of peer rejection). Indeed, evidence does suggest that supportive peer groups and reciprocated friendships can protect against victimisation (Boulton \& Smith, 1994; Boulton, Trueman, Chau, Whitehand, \& Amatya, 1999; Hay, Payne, \& Chadwick, 2004; Hodges, Boivin, Vitato, \& Bukowski, 1999; Pellegrini, Bartini, \& Brooks, 1999). 
Finally, to assess the stability of roles in bullying different methodologies have been used. Few longitudinal studies have employed relative risk analysis of different forms of victimisation (Schäfer et al, 2005). The current study considers both social (peer structure, dominance hierarchies) and individual characteristics that are likely to explain why some children may escape and others remain stable victims. Individual characteristics include the child's sex, age, their behaviour, health status and educational problems at baseline, and the social context they grow up in such as siblings and home situation. Social context variables include the number of friends, rejection of other children, and the social hierarchy of their class.

The aims of the present study among primary school children in the U.K were to investigate: (1) the stability of direct and relational victimisation among primary school children over a period of 2-4 years; and (2) to determine what combination of individual and social factors best predicts remaining involved in victimisation, escaping victimisation or becoming involved in direct or relational victimisation, respectively.

\section{Method}

\section{Design and Subjects}

The present study is a longitudinal investigation involving 17 primary schools (24 classes) in Hertfordshire and North London, U.K. All schools approached to take part in the follow-up study agreed to participate. The baseline (time 1) assessment was carried out with children from year 2 (aged 6-7 years) and year 4 (aged 8-9 years). Children participated in an individual bullying interview at baseline (for further information, please refer to Wolke et al. [2000; 2001a, 2001b], and repeated the 
bullying assessment administered as a questionnaire when the children were in year 6 (last year of primary school), i.e. 2 or 4 years after the baseline assessment (time 2)).

Of the 663 pupils in the 24 classes at baseline, 29 were not assessed [ $\mathrm{n}=14(48 \%)$ absent on assessment days, and $\mathrm{n}=15$ (52\%) non-consent], and 202 pupils were dropouts when the study was carried out at time $2[\mathrm{n}=7(3 \%)$ were non-consent, $n=24$ $(12 \%)$ were absent and $n=171(85 \%)$ had moved to another school]. Of the total 618 pupils in the follow up study (time 2), 157 were new children that were not originally assessed at baseline. Thus, 432 of 663 (65\%) pupils were assessed at the baseline (time 1) and follow-up (time 2). For issues of statistical power the two groups studied over the 2 or 4 year period were collapsed into one follow-up group for analysis.

\section{Procedure}

The study received ethical permission from the University of Hertfordshire Ethical Committee. After securing consent from the head teacher and the individual teachers, written information about the study and a non-consent form (parents were asked to sign if they did not want their child to take part) was passed to all parents via the pupils.

Pupils were individually asked to complete the bullying interview at baseline (time 1) (all interviewers trained and reliability checked), and the bullying questionnaire at follow-up (time 2). The researcher provided a detailed description of what does/does not constitute bullying behaviour, and emphasised the differences between direct and relational forms of bullying. The self-report questionnaire used at follow-up was administered to whole classes $(\mathrm{N}=26-32)$ by a trained psychology postgraduate researcher. Pupils were instructed on the importance of not conferring 
with one another whilst completing the questionnaire, and were asked to complete in silence, unless they needed to ask the researcher a question. The bullying interview and self-report questionnaire both took approximately 10-15 minutes to complete.

Children and parents were free to discontinue with the study at any time. The opportunity to consult with the researcher via telephone or personal consultation in the school if they wanted to discuss any issues related to the study was offered to all involved. No pupils became distressed during the study.

\section{Instruments}

\section{Baseline and Follow-up}

Bullying victimisation- In this section the pupils were asked to complete the bullying interview at baseline (time 1) and the bullying questionnaire at follow-up (time 2). Assessments at baseline and follow-up were identical and included questions adapted from the widely used questionnaire by Olweus (1993): First, pupils were asked if they were ever bullied at school in the last six months by other student/s using any of six forms: (a) hit, kicked, pushed; (b) had belongings taken or damaged; (c) called nasty names; (d) made fun of by others; (e) left out of things on purpose, excluded from the group or completely ignored; (f) other students told lies or spread rumours about them and/or tried to make others dislike them. Questions (a), (b), (c) and (d) indicate direct victimisation at school, and questions (e) and (f) relational victimisation.

Those children who had experienced one or more of these behaviours were asked how frequently these incidents happened during the last 6 months $(1=$ never, $2=$ rarely/hardly ever, $3=$ frequently/about once a week, $4=$ very frequently/more than 
once a week.) For statistical analysis, never and rarely/hardly ever were not considered as regular victimisation, whereas frequently and very frequently accounted for a child being regularly victimised. According to the answers, pupils were classified as being uniquely involved as a direct or relational victim, or involved in both direct and relational victimisation (Whitney \& Smith, 1993; Wolke \& Stanford, 1999; Wolke, Woods, Schulz, \& Stanford, 2001).

We also enquired whether the children were involved in bullying themselves using the same item format. For the purpose of this study we considered "pure" victims as those who were not at the same time involved in perpetration (bully/victims).

\section{$\underline{\text { Baseline }}$}

Peer Nominations - Children were asked to identify (using code numbers) the three children who they liked the most in their class (positive peer nominations), and the three children they disliked most in their class (negative peer nominations). Children were assigned sociometric categories using the procedures described by Coie, Dodge and Coppotelli (1982). Liked-Most (LM) and Liked-Least (LL) nominations from peers were summed for each child and then standardized (z-transformed) within class and school. Social Preference scores (ZLM - ZLL) and Social Impact scores (ZLM + ZLL) were calculated and standardized within class (and school), permitting the computation of the sociometric status classifications of rejected and neglected.

Peer Hierarchies - The methodology used by Schäfer et al. (2005) was used to identify the peer hierarchical structure of each class. The $S D$ of social impact scores 
per class were used to characterise shared social representations of a hierarchical structure. Low scores demonstrate that children have a similar social impact (i.e. a low hierarchical structure). In contrast, high scores illustrate that there are large differences between children, which corresponds to a high degree of hierarchical structuring at the class level. To distinguish between high versus low hierarchical structures, each class was assigned a peer hierarchy value based on the median split. Each individual within the class was assigned the class value to indicate whether they came from a class with high or low hierarchical structuring.

Behaviour Questionnaire - The Strength and Difficulties Questionnaire (SDQ) (Goodman, 1997) was completed by parents at baseline (time 1) to screen for behaviour problems. The 25 items of the SDQ (Goodman, 1997; Goodman, 2001; Klasen et al., 2000) fall into 5 scales of 5 items each: Conduct Problems, Hyperactivity, Emotional Symptoms, Peer Problems and Prosocial Behaviour. For each scale, except for prosocial, higher scores indicate more problems. A total difficulties behaviour score was computed by combining all scales except from the prosocial behaviour scale. The current study reports on total difficulties behaviour scores only.

For categorical analysis, we used Goodman's (1997) cut-off points to identify children in the sample in the clinical range $\left(>90^{\text {th }}\right.$ percentile). The current study focuses on those children classified as having normal/borderline total behaviour difficulties ( $\leq 90^{\text {th }}$ percentile) versus those who had behaviour difficulties within the clinical range $\left(>90^{\text {th }}\right.$ percentile) . 
Health Questionnaire - At baseline (time 1) parents of children completed a standard health questionnaire (Wolke, Woods, Bloomfield, \& Karstadt, 2001) with two sections: a) 7 items about physical health problems (PHP) over the previous 6 months rated on a 7 point scale (none to 6 or more times) (headache, tummy ache, sore throat/ear ache, cold/cough, feeling sick, breathing problems, skin problems), b) 7 items about emotional health problems (EHP) (previously known as psychosomatic health problems) rated according to a 5-point scale (never to most days) (bed wetting, problems going to sleep, nightmares, woken in the night, poor appetite, excessive appetite, worried about going to school). The items used to assess physical health problems and emotional health problems were summed together to construct two variables for the total amount of physical and emotional health problems that children experienced.

Other important variables measured at baseline (time 1) were: (1) whether the child had special educational needs (SEN) (Children at stages 2-5 were considered as having SEN in the current sample or if children received extra learning support either from within the school or an outside party) (Woods \& Wolke, 2004), (2) the total number of times each child was nominated as being liked by peers, (3) the total number of times each child was nominated as disliked by peers, and (4) the child's home situation (whether the child lived with biological parents, single parent or parent's partner.

\section{Statistical Analysis}

The statistical analysis was carried out in three stages: (1) Drop-out analyses (Wolke, Ratschinski, Ohrt, \& Riegel, 1994; Wolke, Söhne, Ohrt, \& Riegel, 1995) of 
baseline measures using chi-square were carried out to determine any significant differences between those children who dropped out of the study between baseline and follow-up, and those children that participated at both times (baseline \& followup), (2) Relative Risk analyses using Epi-info version 6.04D (www.cdc.gov) were carried out to assess the stability or change of direct and relational victimisation between baseline (time 1) and follow-up (time 2) (see Schäfer et al., 2005; see Wolke, Söhne, Riegel, Ohrt, \& Österlund, 1998). Yates’ correction for chi-square analyses was used for the relative risk analyses due to relatively small sample sizes. (3) Logistic regression analyses using backward stepwise models were carried out to determine what combination of factors (at baseline: gender, SEN, child's home situation, school year, number of times nominated as liked by peers, number of times disliked by peers, class hierarchical structure [range from $.45-1.66$, median split cutoff point .97], rejected/neglected sociometric status, behaviour problems in the clinical range, total number of physical health problems, and total number of emotional health problems) best predict remaining involved in victimisation, escaping victimization, or becoming involved in victimisation for direct and relational bullying, respectively. The value for retention in the logistic regression function was set at $\mathrm{p}<.10$.

\section{Results}

Drop-Out Analysis

Those children who participated at baseline and follow-up $(\mathrm{N}=432)$, were compared to those children who dropped out of the study and did not take part in the follow-up study $(\mathrm{N}=202)$. Chi-square analyses revealed a significant difference 
between relational victims and neutral children, and whether the child took part in both studies $\left(\chi^{2}(1, N=579)=7.44, p<.01\right)$. Those children who were classified as relational victims (dropout: $36.9 \%$ ) at baseline were more likely to drop-out of the study compared to neutrals (dropout: $26.2 \%$ ) (Odds Ratio: 1.64, 95\% CI=1.15-2.35). Just considering those children who had moved schools $(\mathrm{N}=171)$; they were significantly more likely to be classified as relational victims (moved school $=46.7 \%$ vs. non drop-out $=37.1 \%$ ) compared to those children who took part in the study both times (Odds Ratio: $1.49,95 \% \mathrm{CI}=1.02-2.17)\left(\chi^{2}(1, N=554)=4.29, p<.05\right)$. No significant difference was found for drop-out rates between direct victims compared to neutrals. An independent analysis t-test revealed that children who dropped out ( $M$ $=1.02$ ) of the study came from classes with a significantly higher peer hierarchical structure compared to children who participated in the original and follow-up study $(M=.97)(t(634)=2.29, p<.05)$. Furthermore, children who had fewer friends $(0-4$ friends) in their class were significantly more likely to drop-out (56.3\% vs. $43.0 \%)$ of the study compared to those children who reported having many friends (8-10 friends) $(43.8 \%$ vs. $57.0 \%)\left(\chi^{2}(1, N=405)=6.21, p<.01\right)($ Odds Ratio: $1.71,95 \% \mathrm{CI}=1.12$ 2.60).

The Stability of Victimisation

\section{Direct Victimisation:}

At baseline, $22.5 \%(n=97)$ of children were classified as direct victims while $25.4 \%(n=117)$ of children were categorised as direct victims at follow-up. A McNemar Test revealed no significant differences between the rate of direct victimisation at baseline and follow-up $\left(\chi^{2}=2.58, p=.12\right)$. Figure 1 illustrates the 
number and percentage of children who remained victims at follow-up (V-V), children who escaped victimisation at follow-up (V-NV), children who became involved in victimisation at follow-up $(\mathrm{NV}-\mathrm{V})$, and those children who remained not involved in victimisation at baseline and follow-up (NV-NV). Children classified as direct victims at baseline had a two fold increased risk of remaining a direct victim at follow-up, $\left(\mathrm{RR}=1.91 ; 95 \% \mathrm{CI}: 1.37-2.66, \chi^{2}=12.57, p<.001\right)$ compared to nonvictims at baseline becoming victims at follow-up (NV-V).

Relative risk analyses computed for the stability of direct victimisation according to gender revealed that victimisation was highly stable for girls over 2 to 4 years $\left(\mathrm{RR}=2.49 ; 95 \% \mathrm{CI}: 1.61-3.85, \chi^{2}=13.74, p<.001\right)$, but not for boys $(\mathrm{RR}=$ 1.45; 95\% CI: $\left.0.87-2.40, \chi^{2}=1.47, p=.23\right)$. Girls had a 2.5 fold increased risk of remaining a direct victim at follow-up $(\mathrm{V}-\mathrm{V})$, compared to non-victim girls at baseline becoming victims at follow-up (NV-V) (Figure 2).

$<$ Insert Figures $1 \& 2>$

\section{Relational Victimisation:}

$10.4 \%(n=45)$ of children were classified as relational victims at baseline and $25.8 \%(\mathrm{n}=119)$ of children at follow-up. A McNemar Test revealed that significantly more children were relationally victimised at follow-up compared to baseline $\left(\chi^{2}=\right.$ $37.53, p<.001)$. Relative risk analysis was carried out to determine the stability of relational victimisation over 2-4 years between baseline and follow-up (Figure 3). There was no long-term risk for children who were classified as relational victims at baseline, to remain a relational victim at follow-up $(\mathrm{RR}=0.98 ; 95 \% \mathrm{CI}: 0.57-1.68$, 
$\left.\chi^{2}=.01, p=0.93\right)$. Relative risk analyses for the stability of relational victimisation according to gender revealed no significant difference for boys $(\mathrm{RR}=1.58 ; 95 \% \mathrm{CI}$ : $\left.0.87-2.88, \chi^{2}=1.29, p=.23\right)$ and girls $\left(\mathrm{RR}=0.48 ; 95 \% \mathrm{CI}: 0.16-1.42, \chi^{2}=\right.$ $1.44, p=.23)$.

$<$ Insert Figure 3 $>$

\section{Remaining and Becoming Involved in Victimisation}

Logistic Regression analyses were carried out to determine the best combination of individual child factors predicting the following dependent variables: (1) remains a direct victim at follow-up versus escaped direct victimisation at followup, (2) become a direct victim at follow-up versus remain a non-victim at follow-up, (3) remains a relational victim at follow-up versus escaped relational victimisation at follow-up, (4) become a relational victim at follow-up versus remain a non-victim at follow-up.

The independent variables were categorised as follows: (a) whether the child had a statement of special educational needs (SEN levels 2-5) (SEN vs. No SEN), (b) the number of times the child was nominated as liked by peers (positive peer nomination), (c) the number of times the child was nominated as disliked by peers (negative peer nomination), (d) peer hierarchical status (low vs. high), (e) whether the child was rejected or neglected by peers (rejected/neglected vs. all others), (f) the child's home situation (lives with biological parents vs. lives with single parent and parent's partner, and lives with single parent vs. all others), (g) gender (males vs. females), (h) school year (year 2 vs. year 4), (i) total number of physical health 
problems (no physical health problems vs. at least one physical health problem), (j) total number of emotional health problems (no emotional health problems vs. at least one emotional health problem), (k) total number of behaviour problems (normal/borderline behaviour problems vs. clinical behaviour problems).

First, a full model was built forcing all 11 independent variables into the prediction function and then removing those variables (backward stepping) which did not make a significant contribution to the model (no significant change in fit when removing variables).

The final model for predicting remaining a direct victim versus escapes direct victimisation at follow-up is shown in table $1\left(\chi^{2}(2, N=52)=11.16 ; p<.01\right)$. Two factors significantly predicted remaining a direct victim versus escaping victimisation: Gender (odds ratio: 5.14, CI (95\%): 1.45-18.17), and positive peer nominations (odds ratio: $1.24, \mathrm{CI}(95 \%)$ : 1.02-1.52). Females compared to males, and children with fewer positive peer nominations compared to children with many positive peer nominations were more likely to remain direct victims at follow up.

$<$ Insert Table 1 $>$

The logistic regression model for predicting becoming a direct victim at follow-up versus remaining non-victimised was non-significant. 
The final model for predicting remaining a relational victim at follow-up versus escaping relational victimisation was non-significant.

The final logistic regression model for predicting becoming a relational victim at follow-up versus remaining a non-victim is shown in table $2\left(\chi^{2}(3, N=234)=\right.$ $11.99 ; p<.01)$. Three factors had a significant impact on predicting becoming a relational victim: Peer hierarchies (odds ratio: 2.00 , CI (95\%): 1.08-3.70), emotional health problems (odds ratio: 1.81, CI (95\%): .97-3.36), and negative peer nominations (odds ratio: .93, CI (95\%): .87-1.01) (tendency at $\mathrm{p}<.06$ ). Those children who were from classes with a high hierarchical structure at baseline, had at least one emotional health problem at baseline, and received many negative peer nominations were more likely to become a relational victim at follow-up compared with those children who were from classes with a low hierarchical structure, had no emotional health problems, and received few negative peer nominations.

$<$ Insert Table 2>

\section{Discussion}

The current study investigated the stability of direct and relational victimisation over a two to four year period among primary school children using risk analysis. Factors that contributed to the prediction of remaining or escaping direct and relational victimisation were also considered. A review of the central findings indicates that children who dropped-out of the study between baseline and follow-up were significantly more likely to have been relational victims than non-victims, had few friends and came from classes with a high hierarchical peer structure at baseline. 
A second key finding identified that children classified as direct victims had a twofold increased risk of remaining a direct victim at follow-up compared to non-victims at baseline becoming victims at follow-up. Results further highlight that direct victimisation was only stable for girls. Being a girl and receiving few positive peer nominations predicted remaining a direct victim. An increased rate of relational victimisation was found at follow-up compared to baseline. In contrast to direct victimisation, no long-term risk was found for children classified as relational victims at baseline to remain relational victims at follow-up. Children who were at baseline in classes with strong peer hierarchies, received negative peer nominations and had emotional health problems were more likely to become relational victims at follow-up 2 to 4 years later.

The majority of the children who dropped out of the study had moved to another school ( $85 \%$ of dropouts). The loss to follow-up was not random but selective. Relational victims as opposed to non victims were significantly more likely to have changed school. Furthermore, children who dropped out of the study had significantly fewer friends and were in more hierarchically organised classes. Having a high dominance relationship established in the class allows for less manoeuvre to make new friends (Schäfer et al., 2005). Friendship can serve as a protective factor, contributing to school enjoyment (Boulton, Trueman, Chau, Whitehand, \& Amatya, 1999; Coyne, Archer, \& Eslea, 2004; Hodges, Boivin, Vitato, \& Bukowski, 1999; Lamarche et al., 2006), while peer rejection can increase victimisation (Boulton \& Smith, 1994; Cillessen \& Mayeux, 2004; Hay, Payne, \& Chadwick, 2004; Pellegrini, Bartini, \& Brooks, 1999). We may speculate that being less popular and relationally victimised could be among the reasons that the children moved to another school. 
The children in the present study were aged between 6-9 years at baseline and 10-11 years of age (final year of primary school) at follow-up. An increased rate of victimisation between baseline and follow-up was found only for relational victimisation. Most studies within the literature have reported a fairly steady decline in direct victimisation through ages 8 to 16 years (e.g. Pellegrini \& Long, 2002; Whitney \& Smith, 1993) which is in line with our findings. The finding that relational victimisation increases with age is consistent with the developmental model proposed by Björkqvist, Lagerspetz and Kaukiainen (1992), and Björkqvist (1994) that relational strategies of victimisation become more frequent and prominent with increasing age (Crick \& Grotpeter, 1995; Keating \& Heltman, 1994; Murray-Close, Ostrov, \& Crick, 2007; Sutton, Smith, \& Swettenham, 1999).

This study considered the stability of victimisation behaviour by means of risk analysis. Previous research has tended to concentrate on peer nomination methods and employed frequency analysis or correlational analysis to discern the stability of bullying behaviour. Furthermore, most studies have relied upon examining the stability of aggressors rather than victims (Crick, Ostrov, \& Werner, 2006; Keltikangas-Jaervinen, Terav, \& Pakaslahti, 1999; Olweus, 1978; Warman \& Cohen, 2000). The current study revealed a two-fold increased risk for remaining involved in direct victimisation behaviour at follow-up. This finding supports some previous work that victimisation behaviour is generally a stable behaviour over a year or more (Boulton \& Smith, 1994; Camodeca, Goossens, Meerum-Terwogt, \& Schuengel, 2002; Dempsey, Fireman, \& Wang, 2006; Kochenderfer \& Ladd, 1996; Sourander, Helstela, Helenius, \& Piha, 2000). When gender differences were considered, results revealed that girls had a 2.5 increased risk for remaining involved in direct 
victimisation behaviour at follow-up, whereas no increased risk was found for boys. Several factors may contribute to girls being more stable in their victimisation. Firstly, single sex groups of girls participate less frequently in direct physical bullying behaviour which involves predominantly male groups, or mixed groups with a higher ratio of boys to girls (Crick \& Grotpeter, 1995; Ostrov \& Keating, 2004). Thus being a female direct victim is highly visible among the peer group and may subsequently lead to them getting a reputation for being a direct victim that is difficult to change. Secondly, female friendship networks are usually tightly knit (Cairns, Perrin, \& Cairns, 1985; Murray-Close, Ostrov, \& Crick, 2007) with few alternative peers from different groups and related to dominance and peer acceptance characteristics (Ostrov \& Keating, 2004). Both reputation and close networks may make it more difficult to escape the victimisation role. Thirdly, previous research has revealed that stable victimised girls were found to be high in impulsivity compared to those who escaped victimisation at follow up (Dempsey et al., 2006). Impulsivity reflects a difficulty in regulating negative emotion and inhibiting negative arousal, and thus could lead to involvement in more direct victimisation. It has also been suggested that female victims who have poor social skills have particular problems to recruit other children to defend them in victimisation situations (Cowie \& Olafsson, 2000). Thus, some or all of these factors may explain why girls were more stable in their victimisation. This finding requires replication and further investigation.

In contrast to the two-fold increased risk found for direct victimisation, no long-term risk was revealed for those children involved in relational victimisation between baseline and follow-up. One explanation is that children who dropped out of the study, mainly because the pupils had left the schools, were over represented as 
relational victims. Thus, those pupils who were most strongly affected by relational victimisation, had few friends, came from highly socially hierarchical classes, and had left the study may have been the most likely to remain stable relational victims. In other contexts, Wolke et al. (1995) has shown how selective dropout can seriously bias long-term conclusions of adverse outcomes. The documentation of selective dropout should be an important consideration in any prospective study of bullying victimisation as shown here.

Alternatively, the lack of stability in relational victimisation can be explained from a developmental perspective. Bullying and victimisation behaviour follows a developmental trajectory which initially begins with direct physical acts of aggression/victimisation, followed by verbal acts and finally relational bullying/victimisation once the child has sufficient cognitive capabilities to plan the relational acts (Björkqvist et al., 1992). The current results illustrate that direct victimisation between the ages of 6-11 years appears to have become a stable behaviour between female victims and bullies. In between the baseline and follow-up assessment the direct bully is reinforced by his/her victim. This leads the aggressor to bully more and the victim to develop maladaptive coping responses in association with possible psychological and physical complaints (low self-esteem, loneliness, depression, anxiety, and sickness) which increase in severity and make victimisation persist longer (Boivin, Hymel, \& Burkowski, 1995; Craig, 1998; Hawker \& Boulton, 2000). Conversely, the current results suggest that relational victimisation has not become a stable behaviour between the ages of 6-11 years although it increases with age (Murray-Close, Ostrov, \& Crick, 2007). In fact, many more pupils were relationally victimised at 10-11 years of age than 2 to 4 years previously. It would 
appear that relational bullying behaviour is still being tried and tested during primary school years and is more prominent as the child gets older and the relationships become more intimate. During primary school years, the peer group is still rapidly changing and developing (Pellegrini \& Bartini, 2001) with children having a variety of different school friends and fallings out over the school year which may contribute to the instability in relational victimisation found in the current research. As the present study only examined victimisation over a 2-4 year time period it remains to be seen whether relational victimisation does actually become a stable behaviour at a later age (during secondary school) when relational bullying has been reported to be used more frequently by girls (Björkqvist et al., 1992; Cillessen \& Mayeux, 2004).

From a theoretical and educational perspective it is important to know what individual characteristics contribute to remaining or escaping being a direct or relational victim, and what factors contribute to becoming a direct or relational victim. Females rather than males, and children with few positive peer nominations were the two risk factors for remaining a direct victim. Friends and being liked protect against prolonged victimisation (Fox \& Boulton, 2006; Lamarche et al., 2006). However, this study cannot reveal anything about the quality and reciprocity of friendships. This would be an important consideration for future long-term studies as friendships have the capacity to buffer against, or defend the victim from aggressive advances in order to serve as a protective factor (Hodges, Boivin, Vitato, \& Bukowski, 1999; Pellegrini \& Long, 2002). We speculate that females who remain as direct victims may not have reciprocated best friends that are able to buffer against the negative and adverse effects of direct, physical victimisation in terms of adaptive coping strategies 
(Cillessen, Jiang, West, \& Laszkowski, 2005) and were thus less likely to be nominated as liked peers.

Emotional health problems and high class hierarchical structure were found to predict becoming a relational victim at follow-up. This finding emphasises the importance of being aware of a child's physical and emotional health as a risk factor for bullying involvement (Wolke et al., 2001a). Relational bullies may have the skills required to recognise that a child is suffering with emotional problems and therefore target this vulnerability using psychological forms of manipulation, which in turn may exacerbate the child's emotional problems leading to a pattern of relational victimisation. Furthermore, having these emotional problems and being relationally victimised is likely to lead to increases in internalising problems (Crick, Ostrov, \& Werner, 2006). The social context in the form of peer hierarchies is an important consideration in addition to individual factors when investigating victimisation. Children who became relational victims at follow-up came from classes with a clearer hierarchical dominance structure at baseline. The strong social ranking of the peer hierarchy at baseline could have hampered the child's ability to interact with peers, and had a negative impact on the development of competent social interactions that were subsequently seized on by aggressors at follow-up. This provides additional support and advances the findings from Schäfer at al. (2005) that victimisation remains more stable in classes that have a high hierarchical peer structure, and that social dominance and hierarchical strategies set limits for access to new peer relationships (Pellegrini \& Long, 2002). 
The strengths of the study include the sufficient sample size, a high follow-up rate for those remaining at the schools and thorough documentation of those lost to follow-up. Conversely, the reliance on self-reports of victimisation behaviour in the form of private interviews or questionnaires may serve as a limitation of the present study. We decided to use self-reports rather than peer nominations as we also wanted to investigate variations in prevalence of bullying involvement between different schools and cross culturally (Wolke et al., 2001b; Woods \& Wolke, 2003). Secondly, the computation of victimisation using peer nominations standardised by class would not have allowed such analysis. The same measure was repeated at follow-up, but instead of a face to face interview it was administered as a questionnaire in class. Thus, the mode of administration may have affected results although high consistency in prevalence has been found using questionnaires and interviews (Smith \& Levan, 1995; Wolke \& Stanford, 1999; Wolke et al., 2001b). Finally, ideally one would have liked to follow the children up after each school year and into secondary school, to minimise the influence of age differences, as some studies have reported that the direct victim role is less stable at younger ages compared to later primary school years (e.g. Boulton \& Underwood, 1992; Kochenderfer-Ladd \& Wardrop, 2001). However, economical constraints prevented annual follow-up.

To conclude, the current study has shed light upon the stability of direct and relational victimisation among primary school children and the important factors related to remaining involved, or escaping from victimisation. Our findings have a number of implications for educational professionals. First, it should be recognised that direct victimisation is likely to become a stable behaviour during the primary school years in a substantial number of pupils with girls at particular risk. Secondly, 
being relationally victimised and socially isolated could be a reason for parents initiating a change of school, and school practitioners should be aware of this. These findings call for the development and implementation of intervention programmes that tackle victimisation at an early age in primary school. Personal and social education should ensure that work centred on friendship in terms of making and maintaining friends is preserved. The implementation of peer networks facilitating peer relationships in combating bullying appear useful (Cowie \& Olafsson, 2000). The findings also have relevance for school professionals, health practitioners and parents to be aware of children showing signs of both physical and emotional health problems, as these appear to be important risk factors for becoming and remaining a victim. 


\section{References}

Björkqvist, K. (1994). Sex Differences in Physical, Verbal, and Indirect Aggression: A Review of Recent Research. Sex Roles, 30, 177-188.

Björkqvist, K., Lagerspetz, K. M. J., \& Kaukiainen, A. (1992). Do Girls Manipulate and Boys Fight? Developmental Trends in regard to Direct and Indirect Aggression. Aggressive Behaviour, 18, 117-127.

Boivin, M., Hymel, S., \& Burkowski, W. M. (1995). The roles of social withdrawal, peer rejection and victimization by peers in predicting loneliness and depressed mood in childhood. Development and Psychopathology, 7, 765-785.

Boulton, M. J., \& Smith, P. K. (1994). Bully/victim problems in middle-school children: stability, self-perceived competence, peer perceptions and peer acceptance. British Journal of Developmental Psychology, 12, 315-329.

Boulton, M. J., Trueman, M., Chau, C., Whitehand, C., \& Amatya, K. (1999). Concurrent and longitudinal links between friendship and peer victimization: Implications for befriending interventions. Journal of Adolescence, 22, 461466.

Boulton, M. J., \& Underwood, K. (1992). Bully/victim problems among middle school children. British Journal of Educational Psychology, 62, 73-87.

Cairns, R. B., Perrin, J. E., \& Cairns, B. D. (1985). Social structure and social cognition in early adolescence. Journal of Early Adolescence, 5, 339-355.

Camodeca, M., Goossens, F. A., Meerum-Terwogt, M., \& Schuengel, C. (2002). Bullying and victimization among school-age children: Stability and links to proactive and reactive aggression. Social Development, 11, 332-345. 
Cillessen, A. H. N., Jiang, X. L., West, T. V., \& Laszkowski, D. K. (2005). Predictors of dyadic friendship quality in adolescence. International Journal of Behavioral Development, 29, 165-172.

Cillessen, A. H. N., \& Mayeux, L. (2004). From censure to reinforcement: Developmental changes in the association between aggression and social status. Child Development, 75, 147-163.

Coie, J. D., Dodge, K. A., \& Coppotelli, H. (1982). Dimensions and types of social status: A cross-age perspective. Developmental Psychology, 18, 557-570.

Cote, S. M., Vaillancourt, T., Barker, E. D., Nagin, D., \& Tremblay, R. E. (2007). The joint development of physical and indirect aggression: Predictors of continuity and change during childhood. Development and Psychopathology, 19, 37-55.

Cowie, H., \& Olafsson, R. (2000). The role of peer support in helping the victims of bullying in a school with high levels of aggression. School Psychology International, 21, 79-95.

Coyne, S. M., Archer, J., \& Eslea, M. (2004). Cruel intentions on television and in real life: Can viewing indirect aggression increase viewers' subsequent indirect aggression? Journal of Experimental Child Psychology, 88, 234-253.

Craig, W. M. (1998). The relationship among bullying, victimization, depression, anxiety and aggression in elementary school children. Personality and Individual Differences, 24, 123-130.

Crick, N., Ostrov, J., \& Werner, N. (2006). A longitudinal study of relational aggression, physical aggression and children's social-psychological adjustment. Journal of Abnormal Child Psychology, 34, 127-138.

Crick, N. R., \& Grotpeter, J. K. (1995). Relational aggression, gender, and socialpsychological adjustment. Child Development, 66, 710-722. 
Dempsey, J., Fireman, G., \& Wang, E. (2006). Transitioning Out of Peer Victimisation in School Children: Gender and Behavioral Characteristics. Journal of Psychopathology and Behavioral Assessment, 28, 273-282.

Fox, C. L., \& Boulton, M. J. (2006). Longitudinal association between submissive/nonassertive social behavior and different types of peer victimization. Violence and Victims, 21, 383-400.

Goodman, R. (1997). The strengths and difficulties questionnaire: A research note. Journal of Child Psychology and Psychiatry, 38, 581-586.

Goodman, R. (2001). Psychometric properties of the Strengths and Difficulties Questionnaire (SDQ). Journal of the American Academy of Child and Adolescent Psychiatry, 40, 1337-1345.

Hawker, D. J. S., \& Boulton, M. J. (2000). Twenty years' research on peer victimization and psychosocial adjustment: a meta-analytic review of crosssectional studies. Journal of Child Psychology and Psychiatry, 41, 441-456.

Hay, D., Payne, A., \& Chadwick, A. (2004). Peer relations in childhood. Journal of Child Psychology and Psychiatry, 45, 84.

Hodges, E. V. E., Boivin, M., Vitato, F., \& Bukowski, W. M. (1999). The power of friendship: Protection against an escalating cycle of peer victimization. Developmental Psychology, 35, 94-101.

Hodges, E. V. E., Malone, M. J., \& Perry, D. G. (1997). Individual risk and social risk as interacting determinants of victimization in the peer group. Developmental Psychology, 33, 1032-1039.

Keating, C. F., \& Heltman, K. R. (1994). Dominance and deception in children and adults: Are leaders the best misleaders? Personality and Individual Differences, 20, 312-321. 
Keltikangas-Jaervinen, L., Terav, T., \& Pakaslahti, L. (1999). Moral reasoning among Estonian and Finnish adolescents: A comparison of collectivist and individual setting. Journal of Cross-Cultural Psychology, 30, 267-290.

Klasen, H., Woerner, W., Wolke, D., Meyer, R., Overmeyer, S., Kaschnitz, W., et al. (2000). Comparing the German versions of the Strengths and Difficulties Questionnaire (SDQ-Deu) and the Child Behavior Checklist. European Journal of Child Adolescent Psychiatry, 9, 271-276.

Kochenderfer-Ladd, B. J., \& Wardrop, J. L. (2001). Chronicity and instability of children's peer victimization experiences as predictors of loneliness and social satisfaction trajectories. Child Development, 72, 134-151.

Kochenderfer, B. J., \& Ladd, G. W. (1996). Peer victimization: cause or consequence of school maladjustment? Child development, 67, 1305-1317.

Lamarche, V., Brendgen, M., Boivin, M., Vitaro, F., Perusse, D., \& Dionne, G. (2006). Do friendships and sibling relationships provide protection against peer victimization in a similar way? Social Development, 15, 373-393.

Maes, S., Leventhal, H., \& deRidder, D. T. D. (1996). Coping with chronic diseases. In M. Zeider \& N. Endler (Eds.), Handbook of coping: Theory, research, applications (pp. 728). Oxford, England: John Wiley \& Sons.

Monks, C. P., Smith, P. K., \& Swettenham, J. (2003). Bullying in infant classes: Roles taken, stability and relationship to sociometric status. Merrill Palmer Quarterly, 49, 453-469.

Murray-Close, D., Ostrov, J. M., \& Crick, N. R. (2007). A short-term longitudinal study of growth of relational aggression during middle childhood: Association with gender, friendship intimacy, and internalising problems. Development and Psychopathology, 19, 187-203. 
Olweus, D. (1978). Aggression in the schools: Bullies and whipping boys. New York: John Wiley and Sons, Inc.

Olweus, D. (1993). Bullying at school: What we know and what we can do. In. Oxford: Blackwell Publishers.

Olweus, D. (1999). Norway. In P. K. Smith, Y. Morita, J. Junger-Tas, D. Olweus, R. Catalano \& P. Slee (Eds.), The nature of school bullying: A cross-national perspective (pp. 28-48). London: Routledge.

Ostrov, J. M., \& Keating, C. F. (2004). Gender differences in preschool aggression during free play and structured interactions: An observational study. Social Development, 13, 255-277.

Pellegrini, A. D., \& Bartini, M. (2001). Dominance in early adolescent boys: Affiliative and aggressive dimensions and possible functions. Merrill-Palmer Quarterly, 47, 142-163.

Pellegrini, A. D., Bartini, M., \& Brooks, F. (1999). School bullies, victims, and aggressive victims: factors relating to group affiliation and victimization in early adolescence. Journal of Educational Psychology, 91, 216-224.

Pellegrini, A. D., \& Long, J. D. (2002). A longitudinal study of bullying, dominance and victimization during the transition from primary school through secondary school. British Journal of Developmental Psychology, 20, 259-280.

Perry, D. G., Kusel, S. J., \& Perry, L. C. (1988). Victims of Peer Aggression. Developmental Psychology, 24, 807-814.

Schäfer, M., \& Albrecht, A. (2004). Tit for tat: Prevalence and stability of aggression and bullying in primary school settings. Psychologie in Erzichung und Unterricht, 51, 136-150. 
Schäfer, M., Korn, S., Brodbeck, F. C., Wolke, D., \& Schulz, H. (2005). Bullying roles in changing contexts: The stability of victim and bully roles from primary to secondary school. International Journal of Behavioral Development, 29, 323-335.

Schuster, B. (1996). Rejection, exclusion, and harassment at work and in schools: an intergration of results from research on mobbing, bullying and peer rejection. European Psychologist, 1, 293-309.

Smith, P. K., \& Levan, S. (1995). Perceptions and experiences of bullying in younger pupils. British Journal of Educational Psychology, 65, 489-500.

Smith, P. K., Shu, S., \& Madsen, K. (2001). Characteristics of victims of school bullying: Developmental changes in coping strategies and skills. In J. Juvonen \& S. Graham (Eds.), Peer harassment in school: The plight of the vulnerable and victimized (pp. 440). New York: Guilford Press.

Smith, P. K., Talamelli, L., Cowie, H., Naylor, P., \& Chauhan, P. (2004). Profiles of non-victims, escaped victims, continuing victim and new victims of school bullying. British Journal of Educational Psychology, 74, 565-581.

Sourander, A., Helstela, L., Helenius, h., \& Piha, J. (2000). Persistence of bullying from Childhood to adolescence - a longitudinal 8 year follow-up study. Child Abuse \& Neglect, 24, 873-881.

Sutton, J., Smith, P. K., \& Swettenham, J. (1999). Bullying and 'theory of mind': A critique of the 'social skills deficit' view of anti-social behaviour. Social Development, 8, 117-127.

Warman, D. M., \& Cohen, R. (2000). Stability of aggressive behaviours and children's peer relationships. Aggressive Behaviour, 26, 277-290. 
Whitney, I., \& Smith, P. K. (1993). A survey of the nature and extent of bullying in junior/middle and secondary schools. Educational Research, 35 3-25.

Wolke, D., Ratschinski, G., Ohrt, B., \& Riegel, K. (1994). The cognitive outcome of very preterm infants may be poorer than often reported: An empirical investigation of how methodological issues make a big difference. European Journal of Pediatrics, 153, 906-915.

Wolke, D., Söhne, B., Ohrt, B., \& Riegel, K. (1995). Follow-up of preterm children: important to document dropouts. The Lancet, 345, 447.

Wolke, D., Söhne, B., Riegel, K., Ohrt, B., \& Österlund, K. (1998). An epidemiological study of sleeping problems and feeding experience of preterm and fullterm children in South Finland: Comparison to a South German population sample. Journal of Pediatrics, 133, 224-231.

Wolke, D., \& Stanford, K. (1999). Bullying in school children. In D. Messer \& S. Millar (Eds.), Developmental Psychology (pp. 341-360). London: Arnold Publisher.

Wolke, D., Woods, S., Bloomfield, L., \& Karstadt, L. (2000). The association between direct and relational bullying and behaviour problems among primary school children. The Journal of Child Psychology and Psychiatry, 41, 9891002.

Wolke, D., Woods, S., Bloomfield, L., \& Karstadt, L. (2001a). Bullying involvement in primary school and common health problems. Archives of Disease in Childhood, 85, 197-201.

Wolke, D., Woods, S., Schulz, H., \& Stanford, K. (2001b). Bullying and victimisation of primary school children in England and Germany: Prevalence and school factors. British Journal of Psychology, 92, 673-696. 
Woods, S., \& Wolke, D. (2003). Does the content of anti-bullying policies inform us about the prevalence of direct and relational bullying behaviour in primary schools? Educational Psychology, 23, 381-401.

Woods, S., \& Wolke, D. (2004). Direct and relational bullying experience among primary school children and academic achievement. Journal of School Psychology, 42, 135-155. 
Figure 1. The relative risk for the stability of direct victimisation

Baseline (time 1)

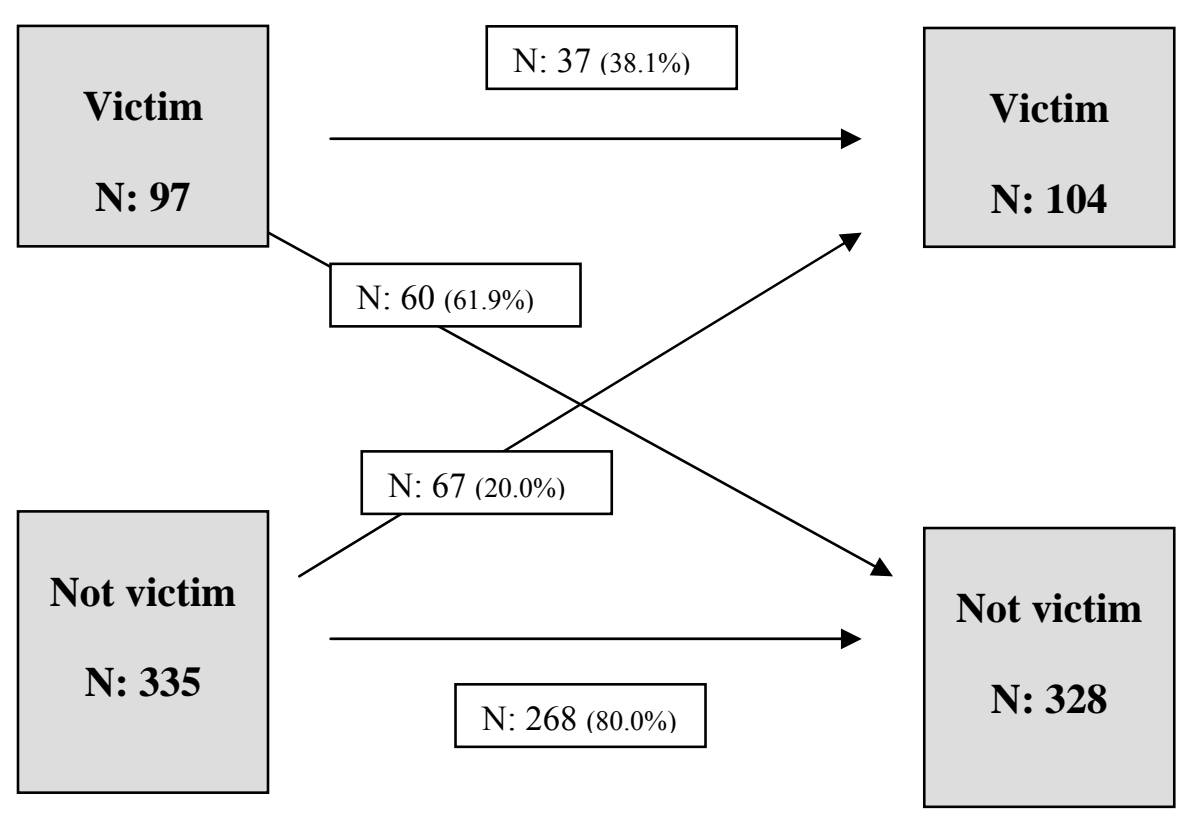


Figure 2. The relative risk for the stability of direct victimisation for girls

Baseline (time 1)

Follow-up (time 2)

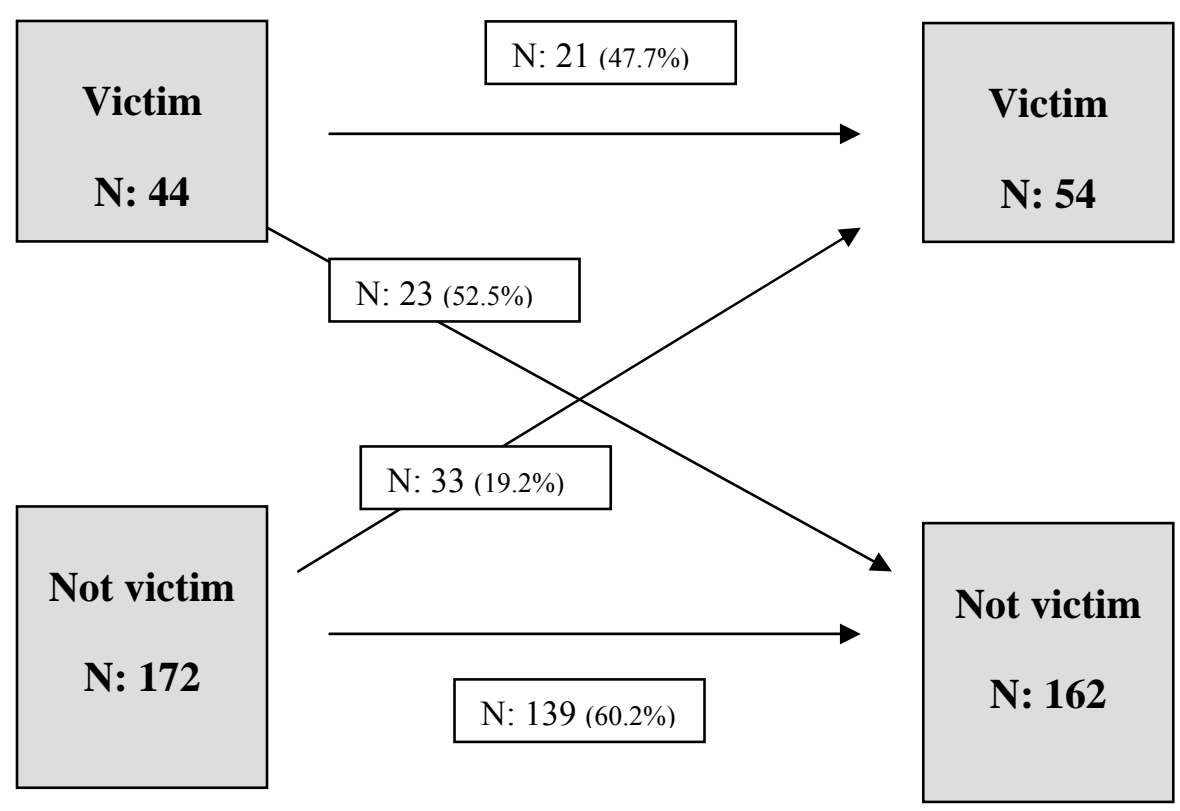


Figure 3. The relative risk for the stability of relational victimisation

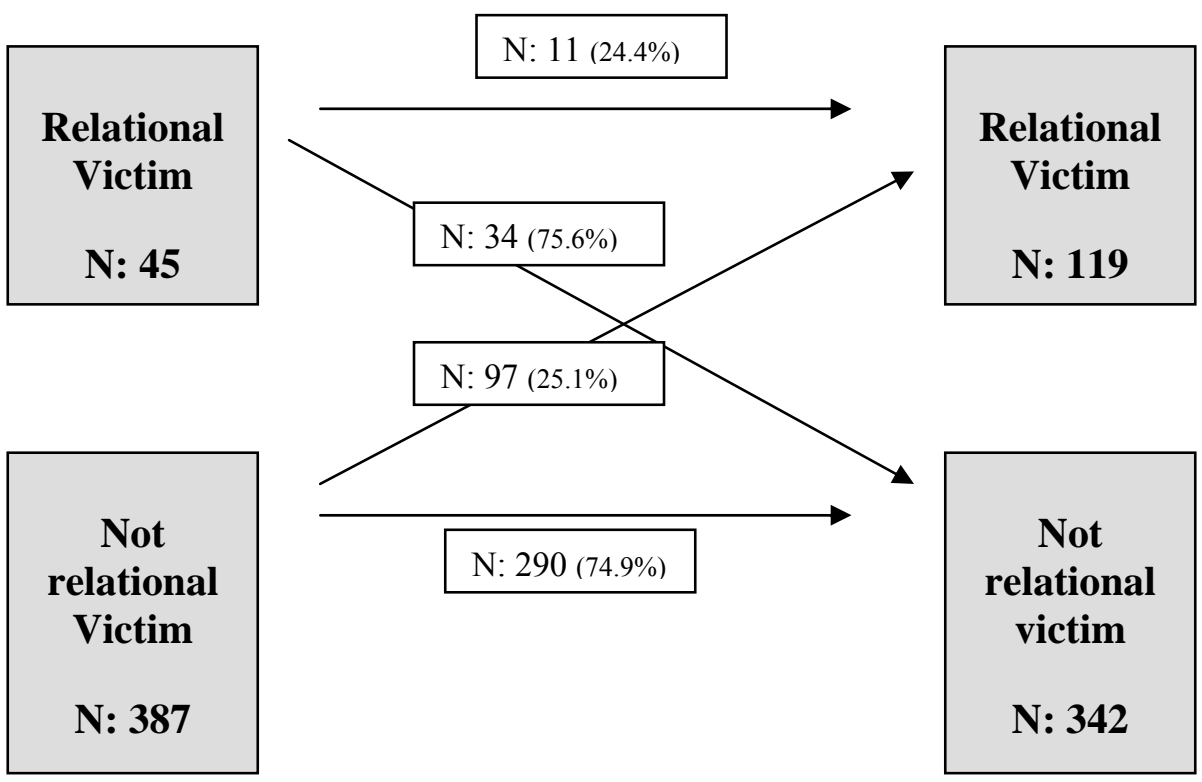


Table 1. Final logistic regression models for remaining and escaping direct victimisation (Backward Stepwise Method)

\begin{tabular}{|c|c|c|c|c|c|c|c|c|}
\hline & \multirow[b]{2}{*}{$\mathrm{B}$} & \multirow[b]{2}{*}{ S.E. } & \multirow[b]{2}{*}{ Wald } & \multirow[b]{2}{*}{$\mathrm{df}$} & \multirow[b]{2}{*}{ Sig } & \multirow{2}{*}{$\begin{array}{l}\text { odds ratio } \\
\text { Exp (B) }\end{array}$} & \multicolumn{2}{|c|}{$95 \%$ C.I. for $\operatorname{Exp}(B)$} \\
\hline & & & & & & & Lower & Upper \\
\hline \multicolumn{9}{|c|}{$\begin{array}{l}\text { Remains direct } \\
\text { victim vs. escaped } \\
(\mathrm{N}=52)\end{array}$} \\
\hline Gender (male) & 1.64 & .64 & 6.45 & 1 & .01 & 5.14 & 1.45 & 18.17 \\
\hline $\begin{array}{l}\text { peer liked } \\
\text { nominations }\end{array}$ & .22 & .10 & 4.47 & 1 & .03 & 1.24 & 1.02 & 1.52 \\
\hline
\end{tabular}


Table 2. Final logistic regression models for remaining and escaping relational victimisation (Backward Stepwise Method).

\begin{tabular}{lllllllll}
\hline \multicolumn{1}{l}{} & & & odds ratio & 95\% C.I. for Exp (B) \\
\hline B & S.E. & Wald & df & Sig & Exp (B) & Lower & Upper \\
\hline
\end{tabular}

Become relational

victim vs. remain

non-victim $(\mathbf{N}=$

234)

$\begin{array}{lcccccccc}\text { Peer hierarchies } & .69 & .31 & 4.87 & 1 & .03 & 2.00 & 1.08 & 3.70 \\ \begin{array}{l}\text { Emotional health } \\ \text { problems }\end{array} & .59 & .32 & 3.5 & 1 & .06 & 1.81 & .97 & 3.36 \\ \begin{array}{l}\text { (at least 1 problem) } \\ \text { peer disliked }\end{array} & -.07 & .04 & 3.35 & 1 & .06 & .93 & .87 & 1.01 \\ \text { nominations }\end{array}$

